Dorota Klimecka-Tatar ${ }^{l}$

\title{
THE WEAR-RESISTANT EVALUATION \\ OF DENTAL MILLING CUTTERS BASED ON CEMENTED CARBIDES
}

\begin{abstract}
This work presents the evaluation of wear resistance of milling cutters. The subjects of this chapter were the milling tools commonly used in dental laboratory. Based on the results it was found, that the milling cutter during the cutting operation can easily become the destruction, resulting in the mass loss and in the first 10 hours of milling cutters work with high efficiency. It is suggested that after 10 hours of milling work, in order to ensure high standards of materials processing, milling cutters should be replaced by new one.
\end{abstract}

Key words: milling cutter, milling tool, cemented carbide

\section{Introduction}

One of the branches of medicine is a dental engineering, based on tooth loss restorations. This section is very large and in order to smoothly move in this area should be combined knowledge of medicine, and the arts which aesthetics associated with the work, and knowledge of materials science. A suitable combination of these areas will allow to create the aesthetic and fully-like natural teeth. The dental technology is applied to the tools used to implement the mapping of teeth. Properly chosen tool allows to facilitate the work, make work more pleasant, with the result that the elements are executed beautifully and what is most importantly the dentures perfectly reflects the natural dentition.

Currently on the market there are many companies involved in the production of prosthetic tools, ranging from micro-motors of different power to the prosthetic milling cutters based on different materials, in ${ }^{1}$ dr inż., Czestochowa University of Technology, Faculty of Management, Institute
of Production Engineering, e-mail: klimt@ wip.pcz.pl 
different forms and with different application to engineering materials. The aim of the tools use is not only facilitate the prosthetics work but the highest aesthetic quality workmanship. With the availability of a wide range of milling cutters dental technician is able to reproduce the incredible accuracy of the conditions in the mouth.

Prosthetic cutters are widely used in prosthetics and are the main tools used for prosthetics materials processing. Their evolution is principally due to the changes in materials innovations, to increase their productivity at work and thus increase efficiency in the office.

\section{Milling cutters as a tool in dental technology}

The milling cutters are the one of the basic tools used to processing materials in prosthetics. Ideally used in the machining of metals, acrylics, ceramics and they are used in milling machines or micro-motors with different power ratings. Due to the shape of the milling cutters it should be can distinguish roller (most commonly used in prosthetics), and the front milling cutters. The roller milling cutters are characterized by blades on the side surface whilst the front milling cutters have blades on the face and they are used to create a very precise workpiece surface. Milling cutters also can be divided based on the geometrical shape of the blades. During the processing of flat surfaces it should be used the cylindrical milling cutters and angled with trapezoidal groove, routers disc, which can be divided into: three-sided with blades performing simple outline straight grooves and one-sided milling cutters used for cutting. Among the wide range of milling cutters distinguish diamond and sintered carbide cutters. Milling cutters made of sintered carbide characterized by greater cutting surface, and are selected for processing materials such as metals, dental composites, acrylic. In contrast, diamond cutters are primarily used in the treatment of ceramic materials and are characterized by a much smaller dimensions than the milling cutters of cemented carbide (SEUnG I. Cha, SoOn H. Hong, GoOK H. HA, BYUnG K. Kim. 2001). 


\subsection{Material characterization of milling cutters}

The milling cutters as it was previously described are divided into two basic groups such as diamond cutters and cemented carbide milling cutters. Cemented carbides cutters in dental laboratories are used more often, however, this type of material in scientific studies is included in the group of composite materials, as sintered metal matrix composites reinforced with particles of carbides. Cemented carbides are sintered hard carbide of high-melting metals such as: titanium carbide (TiC), tantalum carbide (TaC), niobium carbide ( $\mathrm{NbC}$ ), vanadium carbide (VC) or tungsten carbide (WC) and a metal matrix, which are usually cobalt, nickel or iron. The very high hardness values determines the high wear resistance of the composite. However, it is not a material free from defects in spite of the high hardness is fragile, and this defect causes its limited use (DOW T. A., MiLLER E.L., GARRARD K. 2004).

Due to the chemical composition the cementet carbide material is divided into the following groups:

1) WC-Co wit addiotion of $\mathrm{TaC}, \mathrm{NbC}, \mathrm{VC}$ (cutting tools used for iron and non-metallic materials),

2) WC-TiC-Co (mainly used for steel cutting),

3) WC-TiC-TaC, NbC-Co (used in tools for steel cutting) (NING LIU, Chengliang Han, Yudong Xu, Sheng ChaO, Min ShI, JIANPING FENG. 2004).

The simple cemented carbide, is powdered metallurgical material. Previously mentioned composite of e.g. tungsten carbide (WC) particles and a binder - a metallic cobalt (Co). The composite, cemented carbides in the main application is used for metal cutting, and contain more than $80 \%$ of the hard phase - carbides. Additional regular carbonitrides are other important components, especially in species that are gradientaly sintered. The shape of the cemented carbide plate is formed by powder compressing or injection molding techniques and then sintered to reach full density (sintering with the liquid phase)

To explain the contents of carbides in material composition is one of the most important factors in adjusting the ratio of hardness and tough- 
ness of the carbide species. Additionally, the use of the finer particle size of the powder lead to the higher hardness of the carbide (in the same binder phase content).

The amount and composition of the binder controls the impact strength and resistance to plastic deformation of the species. At equal carbides type and grain size, an increased amount of binder will result in a more durable species. However, it will be more susceptible to wear due to plastic deformation. Too low binder content can result in the fragility of the material. Regular carbonitrides, also called $\gamma$ are generally added to increase hot hardness and to form gradients. The gradients are used to connect an increased resistance to plastic deformation and the increase of edge impact strength. Regular carbonitrides concentrated in the cutting edge improve the hot hardness in area where it is required. In addition to the cutting edge structure prevents cracks and fractures as a result of the swarf crushing. Medium to large sized grains of carbides provide cemented carbides wonderful combination of high hot hardness and impact strength (Deng X., Patterson B.R., ChaWla K.K., KoOPMAN M.C., FANG Z.,, LOCKWOOD G., GRIFFO A. 2001, ZAK FANG Z., WANG XU, TAEGONG RYU, KyU Sup HWang, SOHN H.Y. 2009, IMASATO S., ToKUMOTO K., KitAdA T., SAKaguCHI S. 1995). Composite materials based on cemented carbides are used in conjunction with covers created by CVD or PVD methods. The fine or submicron WC grain size are used for the sharp cutting in addition with PVD coatings edges (PVD is processing in order to further increase the strength of the edge). They also benefit from a great resistance to cyclic thermal and mechanical loads. Typical applications are full of carbide drills, full carbide ballnose endmills, cutting and grooving plates, rotary cutters plate and species for finishing (NORdiN M., LARSSON M., HoGMARK S. 2009, LEE J.N. 2007).

\subsection{The types of milling cutters}

The wide breadth of milling cutters shapes made in the latest technologies, thereby improving the work quality which is translates into efficiency. In Figure 1 the different type of cutters are presented. 


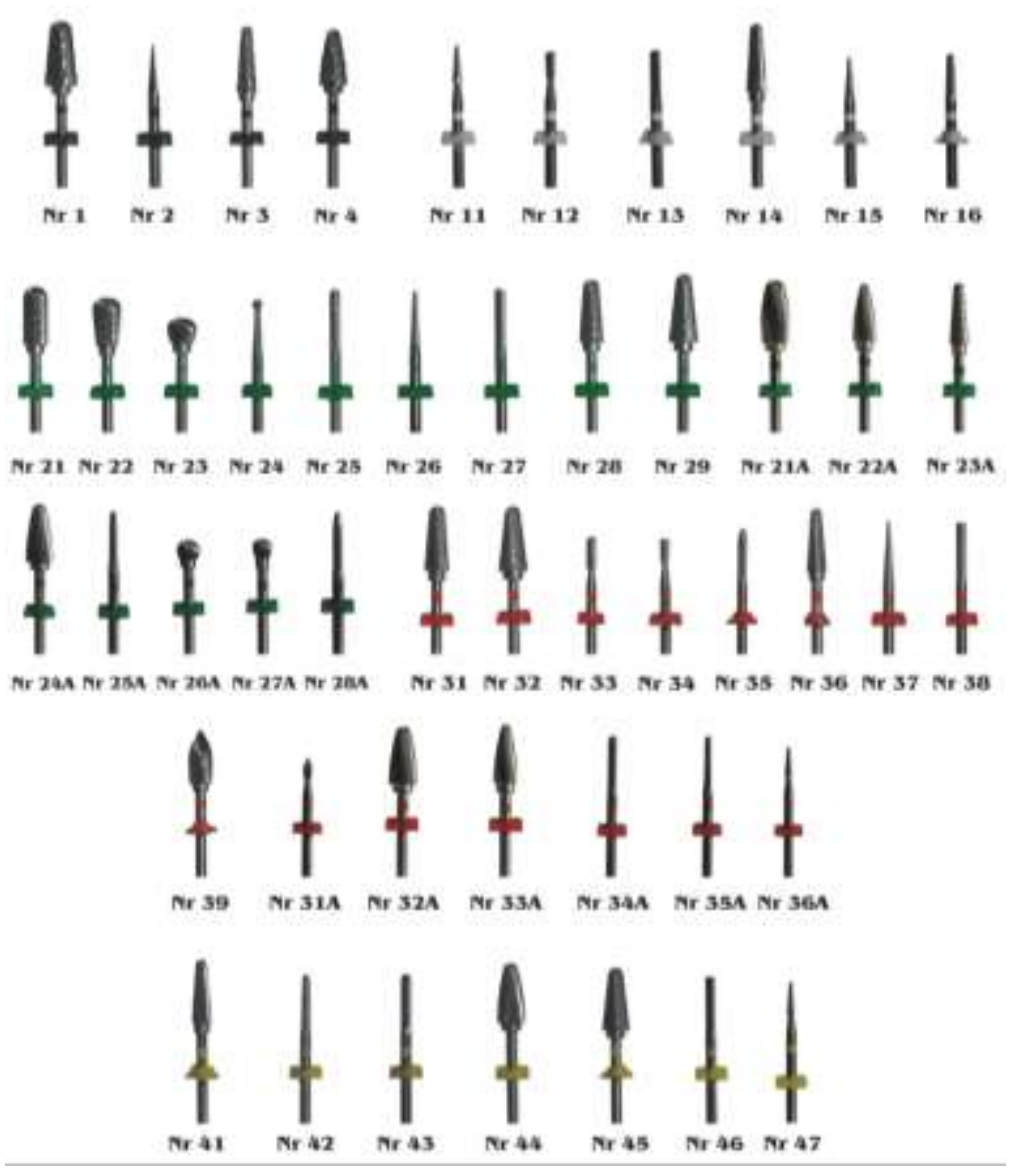

Fig. 1. The types of cutters with different markers and forms

Source: www.denterum.de

All milling cutters depending on the destination have different markings and so:

- cutter marked green are used for the treatment of acrylic and metallic materials,

- cutter marked blue are used for the treatment of acrylic materials,

- cutters marked red are designed for processing of metallic materials only, 
- marked black cutters are used for the treatment of gypsum,

- cutters marked yellow are intended for finishing each type of material.

Among the wide range of milling cutters available on the market most commonly used are cutters made of cemented carbide. With affordable prices and a very good performance at work, are commonly used by prosthodontists.

\section{Experimental}

The cutters in prosthetic dental technology, are the main tools used in the preparation of dental defects supplements by prosthodontists. Perfectly made work is dependent on the used tools, if the tools are not appropriately selected to implemented plan the end result will not respond to earlier assumptions. In this chapter the results of measurements milling cutters wear two different manufacturers will be presented.

The milling cutters wear was determined by measurement of the cutters weight loss after prolonged grinding imitating the work of a dental technician. The study was based on measuring the weight loss of the cutter after fifteen standing abrasion cycles. Also measurement of the weight loss of the anti-friction sample were made (anti-friction sample made of stainless steel). In the study cemented carbide cutters have been subjected. First cutters, it was commercial tool made by MACRO company (for metal treatment, marked green, cutters in this category are characterized by high thickness abrasive surface (Fig.2). The second was cemented carbide cutter made by German company HARICO (for coarse removal of all dental materials, for removal of large surfaces), marked blue, with TiAlN surface coating (Fig..3). 

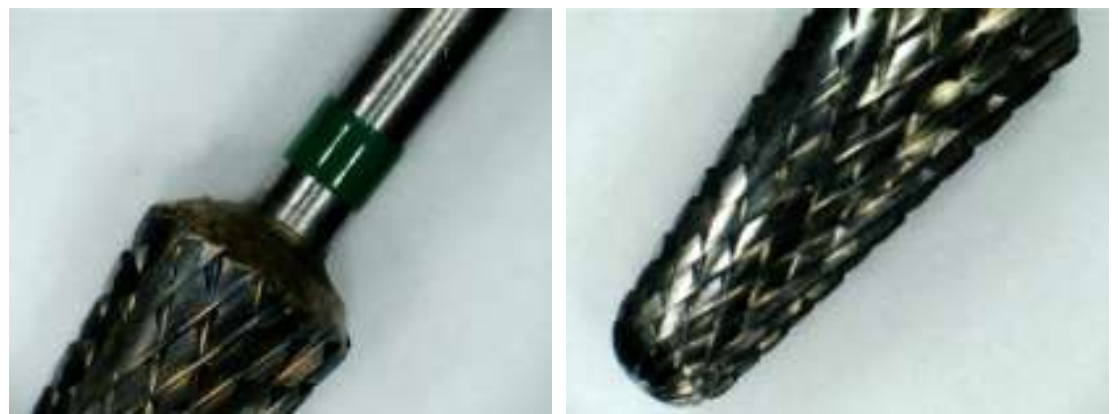

Fig.2. The image of sample 1 - cutters made by MACRO company Source: own study
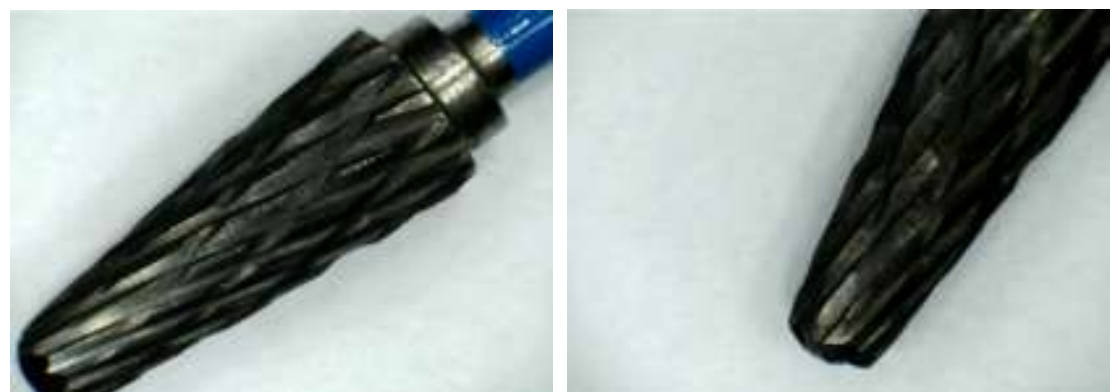

Fig.3. The image of sample 2 - cutters made by HARICO company Source: own study

At any followed hour of the newly started abrasion test the interruption has placed and deletion of the tested milling cutter from micro-motor Marathon N7, then the milling cutter undergoes to precise cleaning of the residual machined material and weighed with a precision about $0,1 \mathrm{mg}$. Experiment methodology was as follows:

- milling cutters preparing,

- setting of micro-motor and handpiece with a stationary position

- setting a constant speed on the micro-motor

- immobilization of stainless steel cubes, to do not to move during the test, 
- measurement of cutters abrasion resistance based on the weight loss of the tested cutters.
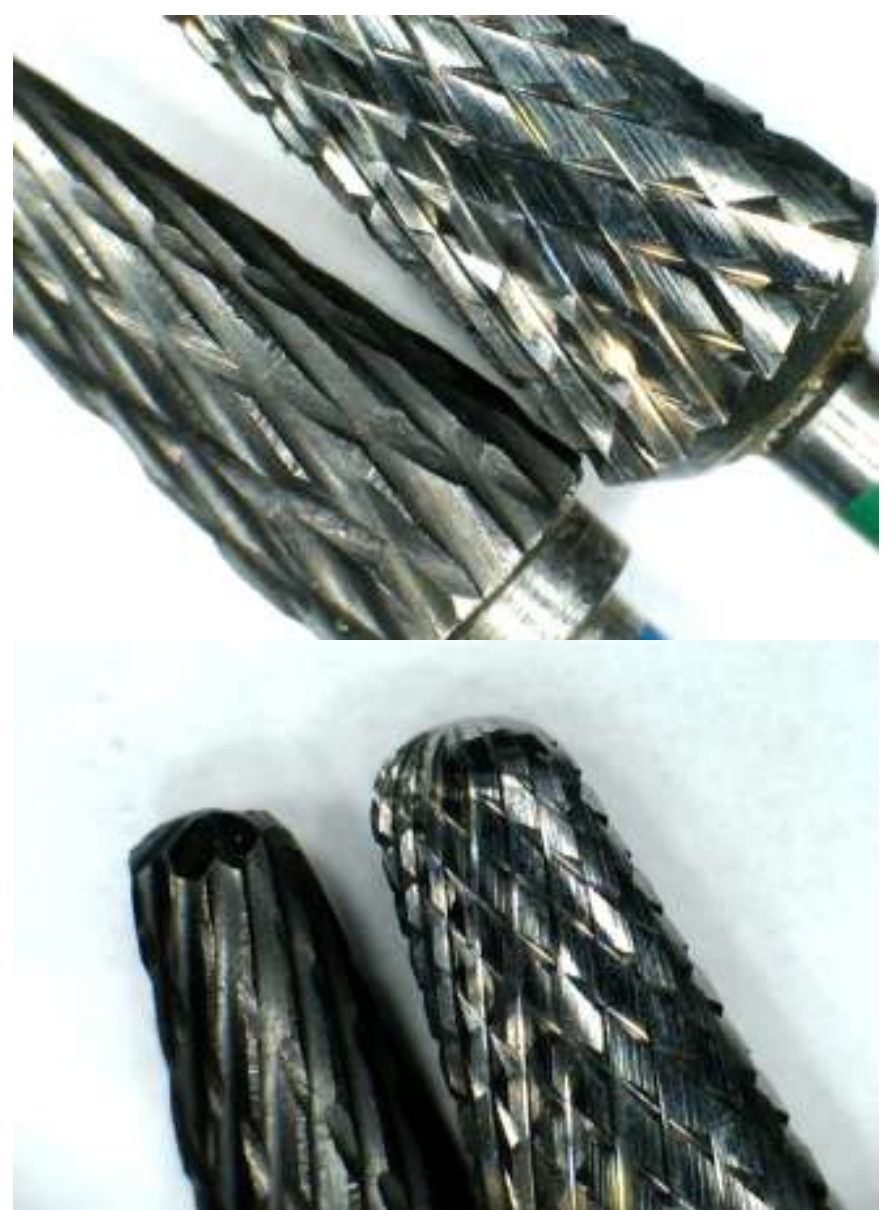

Fig.4. The comparison of the blades of sample 1 (left) and 2 (right) Source: own study

The blade profiles incorporate rake and relief angles for a clean finish while clearing excess materials away quickly. The unique blade design cuts without gouging or striations often left by diamond instruments. 
Both of milling cutters have specific cross-blade profile. The blades are flatter and thus more acute. It can be seen that the milling cutter blade on the green (sample 2) are characterized by more cutting edges. The waveform incisions (,fin") on the face of the milling cutters allows a preparation perpendicular to the grinded surface

\section{Results}

The Fig. 5 presents the results of measurements of sample weight change (milling cutters made of cemented carbides) during 15 cycles (in total during 15 hours) of abrasion. After the first hour of the study, there were no explicit loss of the milling cutter mass, while the anti-abrasive material was relatively large loss of the mass up to two grams of material. During two hours of abrasion neither one of them lost more than $0,01 \mathrm{~g}$. In further abrasion tests the situation began to change.

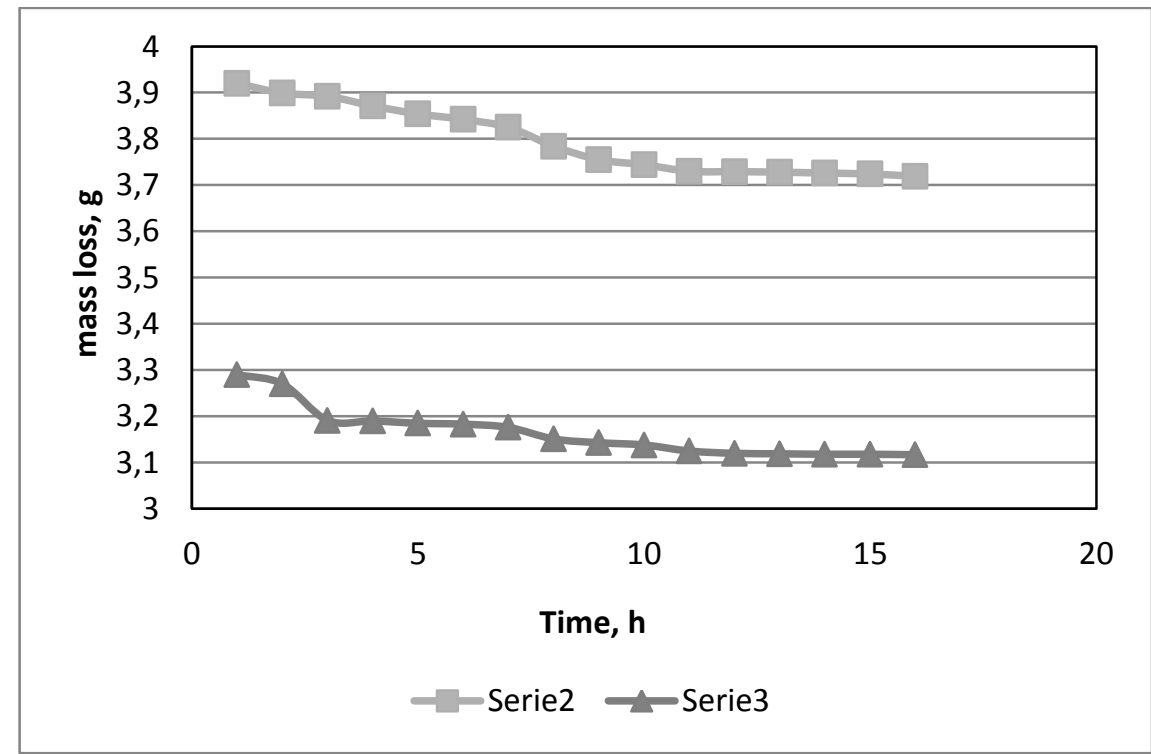

Fig.5. The comparison of sample1 and 2 masschange (cutters made of cemented carbides) during 15 hours.

Source: own study 


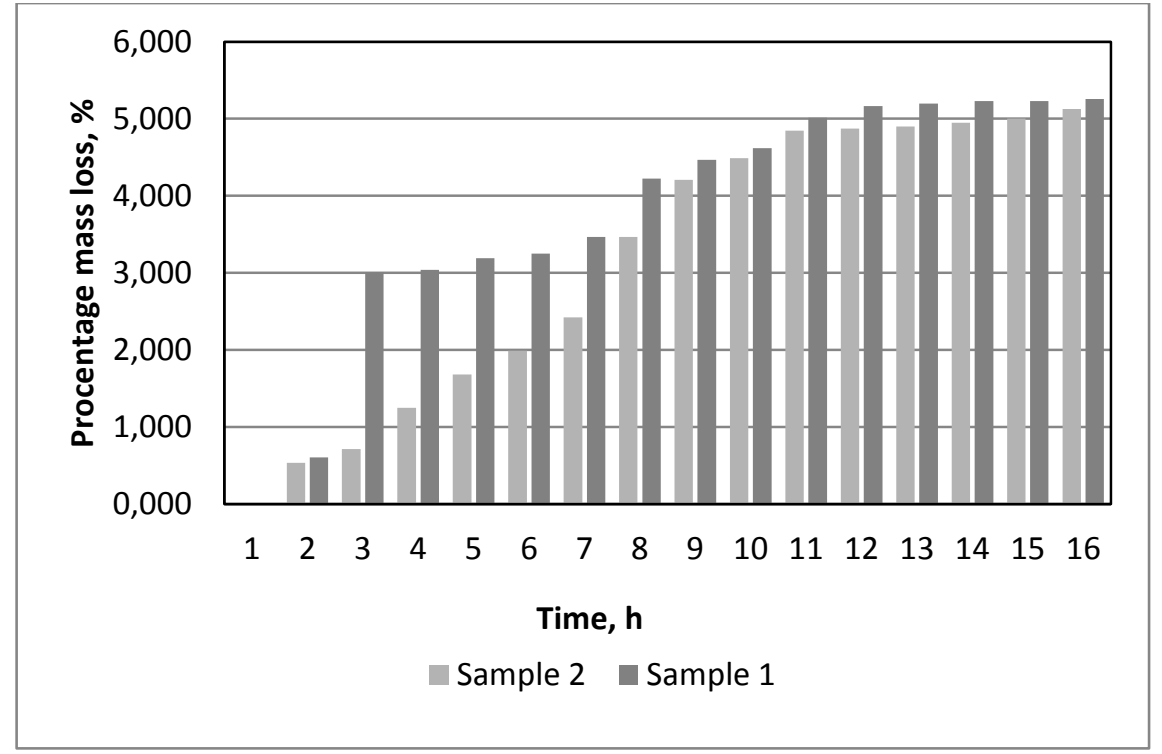

Fig.6. The comparison of sample1 and 2 procentage mass change (cutters made of cemented carbides) during 15 hours.

Source: own study

In the case of sample 2 in the third hour there was a significant weight loss, reaching almost $3 \%$ of the initial weight of the milling cutter, whereas the sample 1 was abraded in proportion to the time of the test, after 3 hours of abrasion in this case the weight loss was slightly more than $1 \%$ (Fig.6). It should be noted that, despite considerable differences in mass loss of sample 1 and 2 in the first 10 hours of abrasion, the maximum loss for both milling cutters made of cemented carbides ranged around 5\%. Whereas after 12 hour of the study there were no significant changes in mass (loss mass on the same level), and there was no further change in mass of the anti-abrasive sample. This indicates that only during 10 hours abrasion the cutters blade work efficiently and effectively, after which time they lose their basic cutting properties. This is important information for dental technicians that after about 10 hours of work such 
blades should be replaced by new ones.

Analyzing the results of the study it can be seen that the sample number 2, which was (marked with a green) has utter a finer cutting surface and according to the statistical data this tool was expensive, so in an objective assessment of the purchaser should be a better milling tool, but the study showed significant mass loss, which testifies to its faster destruction. In contrast, sample number 1 (marked with a blue) has a much greater cutting surface and according to statistic prices of milling tool was definitely cheaper, which in the sight of the purchaser took potentially worse place, but the study showed, that is more durable and usefulness. The study did not take into account the difference in density of the milling cutters materials which may affect the results of the sample mass change, and therefore also the loss of anti-abrasive samples were compared. The milling cutter labeled as Sample 1 caused far greater destruction on it, and a loss was nearly $45 \%$ mass (sample number 2 only $3 \%$ by mass). However, the study showed that the price of a product does not always go accompanied with quality of milling tool.

\section{Summary}

Based on the results presented in this chapter it was found:

- the milling cutter during the cutting operation can easily become the destruction, resulting in the mass loss,

- in the first hours of milling cutters work are the most effective, because it had the highest mass losses of anti-abrasive samples,

- after 10 hours of milling work, in order to ensure high standards of materials processing, milling cutters should be replaced by new one. 


\section{Bibliography}

1. LEE J.N. 2007. Tool path generation method for multi-axis machining of helical milling cutter with specific cross-section profil. J Mech Sci Technol 21. Pp. 1644-1650.

2. Deng X., Patterson B.R., Chawla K.K., Koopman M.C.' Fang Z., LOCKWOOD G., GRIFFO A. 2001. Mechanical properties of a hybrid cemented carbide composite. International Journal of Refractory Metals and Hard Materials Vol.19/4-6, pp. 547-552.

3. ZAK FAng Z., WANG Xu, TAEgOng RYU, KyU SuP HWANG, SOHN H.Y. 2009. Synthesis, sintering, and mechanical properties of nanocrystalline cemented tungsten carbide $-A$ review. International Journal of Refractory Metals and Hard Materials. Vol.27/ 2, pp., 288-299.

4. Seung I. Cha, Soon H. Hong, Gook H. Ha, Byung K. Kim. 2001. Mechanical properties of WC-10Co cemented carbides sintered from nanocrystalline spray conversion processed powders. International Journal of Refractory Metals and Hard Materials. Vol.19/4-6, pp. 397-403.

5. Imasato S., Tokumoto K., Kitada T., SAKaguchi S. 1995. Properties of ultra-fine grain binderless cemented carbide 'RCCFN'. International Journal of Refractory Metals and Hard Materials. Vol. 13/ 5, pp. 305-312.

6. Nordin M., LARSSON M., HOGMARK S. 2009. Mechanical and tribological properties of multilayered PVD TiN/CrN, TiN/MoN, TiN/NbN and TiN/TaN coatings on cemented carbide. Surface and Coatings Technology. Vol.106/ 2-3, pp. 234-241.

7. Dow T. A., Miller E.L., GARrard K. 2004. Tool force and deflection compensation for small milling tools. Precision Engineering. Vol. 28/1, pp $31-45$.

8. Ning Liu, Chengliang Han, Yudong Xu, Sheng ChaO, Min Shi, JIANPING FENG. 2004. Microstructures and mechanical properties of nanoTiN modified TiC-based cermets for the milling tools. Materials Science and Engineering: A. Vol.382/1-2, pp. 122-131 